\title{
TORNAR-SE PESQUISADOR: A ESCOLHA PROFISSIONAL COMO UM PROCESSO
}

\author{
Rita de Cássia Ramos Louzada* \\ João Ferreira da Silva Filho\#
}

RESUMO. Este trabalho apresenta dados de uma pesquisa qualitativa realizada com pós-graduandos de um curso de excelência, na área biomédica. Como referencial teórico foram usadas, prioritariamente, as produções de Pierre Bourdieu. Nossos achados apontaram para a necessidade de enfocar a escolha profissional em ciências biomédicas como um processo, tendo em vista: (1) os inúmeros fatores que atravessam os percursos acadêmicos e (2) o impacto produzido pelas intensas transformações observadas no campo científico..

Palavras-chave: escolha profissional, pesquisa biomédica, pesquisadores em pós-graduação.

\section{BECOMING A RESEARCHER: THE PROFESSIONAL CHOICE AS A PROCESS}

\begin{abstract}
Data collected from a qualitative research carried out with postgraduate Biomedical students are provided. Theoretical framework constructed by Pierre Bourdieu was privileged. Results show the need to focus the professional choice in biomedical sciences as a process, bearing in mind: (1) the countless factors that pervade the academic trajectory and (2) the impact produced by deep transformations in the academic field..
\end{abstract}

Key words: Professional choice, biomedical research, graduate students as researchers.

\section{PARA HACER UN INVESTIGADOR: LA OPCIÓN PROFESIONAL COMO DE PROCESO}

RESUMEN. Este trabajo presenta datos de una investigación cualitativa, llevado a través con pós-graduandos de un curso de excelencia, en el área biomédica. Fue utilizado como referencial teórico, con prioridad, las producciones de Pierre Bourdieu. Nuestros resultados habían señalado con respecto a la necesidad para enfocar la opción profesional en ciencias, como proceso, debido a: (1) los factores innumerables que cruzan los pasos académicos y (2) el impacto produjeron para las transformaciones intensas observadas en el campo científico..

Palabras-clave: Opción profesional, investigación, investigadores después de-graduandos.

O clássico ensaio de Weber (1982) intitulado "Ciência como vocação" - originalmente um discurso pronunciado na Universidade de Munique, em 1918 logo de início apresenta uma questão importante: "Quais as perspectivas para o estudante formado que resolve dedicar-se profissionalmente à ciência na vida universitária?" (p. 156). Certamente a questão formulada por Weber naquele texto tem sido colocada por todos aqueles que, no momento da escolha profissional, apresentam ou apresentaram algum interesse pela atividade de pesquisa.
Assim colocada, a questão também se articula ao objetivo deste trabalho: abordar, a partir de relatos de um grupo de pós-graduandos brasileiros, o processo de escolha da atividade de pesquisa como profissão. A expressão "processo de escolha" não é irrelevante no caso deste trabalho, como veremos adiante.

Vale lembrar, seguindo Hobsbawm (1995), que a ciência, já bastante visível no início do século XX, não foi considerada indispensável para a vida diária senão a partir do último terço desse mesmo século, e não apenas no mundo desenvolvido. $\mathrm{O}$ que se acompanhou

* Doutora em Saúde Mental. Professora Adjunta do Departamento de Psicologia Social e do Desenvolvimento, Universidade Federal do Espírito Santo-UFES.

\# Doutor em Psiquiatria. Professor Titular do Departamento de Psiquiatria e Medicina Legal, Unversidade Federal do Rio de Janeiro-UFRJ. 
a partir daí foi um vínculo estreito entre tecnologia e pesquisa científica dominando o boom econômico no fim do milênio. O que se acompanhou a partir daí? Os cientistas cresceram em número por todo o planeta, mas segundo esse autor, representavam apenas a ponta de um iceberg muito maior, que trazia toda uma mãode-obra científica potencial: os candidatos a cientista. De maneira geral e cada vez mais, os cientistas passaram a ser selecionados através de uma "tese doutoral". Para caracterizar esse crescimento, Hobsbawm (1995) afirma que, no final dos anos 80, o país ocidental avançado típico produzia cerca de 140 desses doutorandos/ano para cada milhão de habitantes. Ou seja, pensar na carreira de pesquisa, a partir de determinado momento, passa a ser sinônimo de pós-graduação.

Mas seria apenas isso? Escolher ser pesquisador, cursar a pós-graduação... Como seriam feitas essas escolhas e como elas estavam sendo sustentadas em nosso meio? Essas eram perguntas que permaneciam.

Um trabalho recente, assinado por Carmo, De Meis, Lannes, Velloso e De Meis (2003), nos traz algumas informações relevantes: a partir do estudo dos ritos de passagem existentes na academia brasileira, os autores assinalaram, entre outras conclusões, que a defesa da tese deixou de ser um rito importante, tendo sido substituída pela publicação de artigos. Este sim é um momento crucial para a definição dos caminhos acadêmicos.

Nossa abordagem, afinada com a produção de Bourdieu (1982, 1989, 2001), pretende refletir sobre esse quadro. Faz-se mister enfocar, mais do que os ritos, os critérios, a linha-limite a partir da qual o sujeito é considerado selecionado ou não, competente ou não, mais consagrado ${ }^{1}$ ou menos, e além disso, as condições e relações existentes no meio científico.

Bourdieu (1989) usa para ajudar a pensar o processo de ordenação o exemplo das seleções escolares: sua pergunta, provocadora, relaciona-se à diferença existente entre o último colocado num concurso e o primeiro reprovado. A distância entre os desempenhos costuma ser muito pequena, de décimos por vezes, o que, em rigor, não estabelece nenhuma grande distinção; mas depois da divulgação do resultado, todo um novo mundo se apresenta ao aprovado - pensando aqui na pós-graduação - novos

\footnotetext{
"L`operation de division qui distingue, dans le continuum des performances [...] deux populations séparées, et pour la vie, est une acte de consécration ou, si l’on préfère, d’ordination qui [...] institue un ordre, c'est-à-dire, une division légitime, magiquement produite et juridiquement garantie, du monde social[...]" (Bourdieu, 1989, p. 141).
}

amigos, novos professores, uma determinada maneira de vestir e conduzir-se, locais e eventos a freqüentar, etc., que vão caracterizando um aluno de determinado departamento/unidade. Para o reprovado, ao contrário, nenhum novo mundo, apenas a sensação - individual, é bom que se frise - de incompetência. Mas o que importa pensar, segundo o mesmo autor, é: afinal qual é a média para aprovação? Que experiência se exige do candidato? E por último, mas não menos importante: por quem e como esses critérios são definidos? Dito de outra maneira, para compreender o que ocorre num determinado campo - científico, no nosso caso - há que se ter clareza quanto a seu movimento, suas marcas históricas.

Vale lembrar que, para Bourdieu (2001), a ciência se configura como campo, numa luta constante de grupos e indivíduos pelo poder de nomear, pelo poder de dizer o que é - e o que não é - cientificamente relevante.

Levando em conta esse referencial, podemos perceber em outros autores, tanto em nível internacional (NRC, 1998; NSF, 2000; Pourmir, 1998; Slaugter \& Leslie, 1999; Teichler, 1997) quanto nacional (Alvarez, 2004; Catani et al., 1999; Jorge, 1999; Leta \& De Meis, 1996; Peixoto, 1994; Reis, 1998), que a atividade acadêmico-científica vem se transformando rapidamente nos últimos anos. Tais reflexões não devem, a nosso juízo, ser negligenciadas quando pensamos a escolha da profissão de pesquisador.

\section{MÉTODO}

Os dados apresentados neste artigo fazem parte de uma pesquisa mais ampla ${ }^{2}$, de caráter qualitativo, com um grupo de pós-graduandos (mestrandos e doutorandos) brasileiros $(n=21)$, de ambos os sexos, da área biomédica e da faixa etária entre 23 e 52 anos. Todos os estudantes estavam regularmente matriculados num mesmo programa de pós-graduação, nível de excelência.

Todos os sujeitos foram entrevistados individualmente em seu local de formação. As entrevistas foram conduzidas conforme o método de história de vida e submetidas à análise de conteúdo (temática) (Bardin, 1987). No caso deste trabalho, divulgamos o material encontrado nos relatos referente à escolha profissional e subtemas correlatos.

\footnotetext{
Trata-se de parte dados da tese de doutoramento da primeira autora. Projeto aprovado pelo Comitê de Ética em Pesquisa do IPUB/UFRJ.
} 
Além disso, utilizamos dados oriundos da observação participante realizada no local de formação dos sujeitos durante os anos de 1999 e 2000.

\section{A PESQUISA}

Os relatos mais comuns a respeito da escolha profissional em ciências mostraram que há um trabalho a ser feito para que o aluno se "torne pesquisador", expressão que surgiu nas entrevistas. Este trabalho parece atravessado por inúmeras variáveis, e vai se dando no percurso da pesquisa. Ao que parece os ritos acadêmicos são peças fundamentais, eles instituem algo (Bourdieu, 1982). São os ritos (publicar, estabelecer uma colaboração, obter financiamento, defender a tese, etc.) e o sucesso nesses momentos que vão produzindo (ou não) o pesquisador.

O reconhecimento, depois do sucesso em determinados ritos, não é o único modo de ir tornando-se pesquisador. Esse processo pode ser ainda mais sutil e gradativo. Pequenos gestos e declarações por parte de quem é reconhecido (chefe, orientador) podem ser reveladores. Isso é o que parece indicar Carmo (2001), que, durante a observação de um seminário com pós-graduandos, presencia a seguinte situação:

Em determinado "journal"3, apresentado por um aluno de doutorado, o chefe, não estando a concordar com as interpretações dadas pelo apresentador, se interessa pelo que um aluno de IC [iniciação científica] comenta. Vira-se em seguida para o observador e diz que ali há um pesquisador em potencial...[O aluno ao] ser publicamente elogiado (pesquisador em potencial), ganha prestígio e visibilidade entre os pares... (p. 64) [grifo no original].

Um elogio ou uma crítica em público podem produzir algum efeito sobre a formação de um pesquisador? Talvez essa seja uma questão relevante num ambiente como este, de alta competitividade.

Latour (1989) também investiga como alguém se torna cientista. Sua abordagem, de caráter antropológico e apoiada na observação das atividades de um chefe de laboratório, deixa claro que não há como dicotomizar as atividades internas (de pesquisa propriamente dita, as ocorrências no laboratório) e as externas ao laboratório/área de conhecimento

3 Journal" aqui significa "journal club": encontro periódico da equipe de pesquisadores para a discussão de artigos científicos. (obtenção de financiamentos, negociações políticas, estabelecimento de colaborações, etc.). Esse autor aponta para a existência de autores que marcam o aspecto externalista, ou seja, ressaltam a mobilização política na obtenção de recursos para a manutenção da atividade; e outros que fazem o oposto, restringindo suas abordagens ao que se faz no interior do laboratório/área de conhecimento. Para Latour (1989) essa é uma separação indevida; o cientista, para ele, precisa conjugar ambas as atividades (interna e externa).

Embora consideremos interessante a abordagem de Latour (1989), damos ainda maior valor a outra forma de ver a questão, mais vigorosa, proposta por Seligmann-Silva (1994): a multiterritorialidade. Tal orientação - marca dos pesquisadores do campo da saúde mental \& trabalho - obriga a uma articulação, necessária, entre aspectos macro e microssociais, valorizando a subjetividade como algo totalmente imerso nesse contexto, do qual não se pode descolar. Seguimos também por essa via. Entendemos a "escolha profissional" - que poderia ser apenas vista como decisão pessoal - como algo muito mais complexo, que se dá a partir de determinadas decisões, sim, mas também em condições e relações sociais bastantes específicas.

Nas falas de nossos entrevistados, de maneira geral, pudemos ver que a escolha profissional foi acontecendo no tempo, daí nossa preferência pela expressão "processo de escolha profissional". Alguns não pensavam em ser docentes pesquisadores, apenas haviam procurado a instituição para cursos de atualização; mas depois foram "interessando-se mais" pela atividade de pesquisa e envolvendo-se em novas atividades/cursos até chegar à pós-graduação, como no caso dessas duas doutorandas:

“[...] dei mais de 10 anos de aula, passei por todas as séries. Na década de 90 eu vim fazer um curso [...] soube de um curso que tinha [aqui], pra professores, não sei o quê... curso de férias, né? Aí um amigo meu que estava fazendo o curso me inscreveu, eu vim pra cá sem saber que curso que era, qual era o assunto que era, não sabia o que que eu vinha fazer aqui... Ele disse: vai lá, tal dia, tal hora. Aí vim, era o primeiro curso de férias pra professores... Aí eu fiz o curso, aí no final do curso eu fui convidada por uma das monitoras, já era aluna de doutorado do $\mathrm{X}$ [orientador], pra trabalhar no laboratório. Existia um grupo começando a trabalhar com determinado assunto... é... com bolsa de aperfeiçoamento, uma coisa que não existia muito [...] E aí acabava os dois anos depois a 
gente ia embora, né? E... vários alunos foram embora. Quando chegou a minha vez de ir embora... o X [orientador] perguntou se eu não queria ficar. Eu estava acabando um trabalho. Eu falei de ficar até o trabalho terminar, que ele não se preocupasse com bolsa, nada disso que eu não ia deixar o trabalho no meio, né? E aí uma semana depois veio uma proposta de eu entrar no mestrado..." (S. 1)

"Depois que me formei eu fui dar aula. E aí dava aula em duas escolas...escola de $1^{\circ}$ grau, né? [...] Um dia me chamaram pra trabalhar num hotel, como recepcionista, curto tempo, mas pra ganhar em dólar... Mas foi exatamente nessa mesma semana que um outro professor me chamou pra fazer um curso de férias aqui. Aí na época fiquei assim: vou fazer o curso ou vou ser recepcionista lá no hotel, ganhar uma grana [...] Aí vim, fiz o curso de férias. Aí na semana seguinte tava tendo um outro, aí eu me inscrevi nesse curso, vim fazer. Adorei, né? Achei o curso o máximo! Podia falar bastante! Questionava, falava, adorava! No primeiro curso eu ficava meio assim, mas achei ótimo! Aí no segundo eu arrebentei...Eu falava pra caramba, tudo era eu, questionava, blá, blá, blá, eu estava assim... no auge, né? E aí o Y [orientador] me chamou pra vir trabalhar aqui com ele, né? [...] Ele dizia: você não quer ir pra bancada, fazer experiência? "Não, esse negócio de bancada não", eu dizia... Nem sabia o que era bancada [risos], mas não queria...Aí ele falou assim, uma coisa que realmente eu não tive como sair: "Vem cá, você dá aula de ciências e nunca fez ciência na sua vida?" Aí realmente eu me senti mal, falei: "E realmente eu não sei o que que é ciência de verdade"...Aí eu vim pra bancada, aí também não quis outra vida!"' (S. 2)

Outros estudantes, diferentemente, revelaram interesse antigo pela pesquisa, relacionado esse interesse a características pessoais, que avaliavam como importantes para a atividade científica.

"Isso [interesse pela pesquisa] era antes de entrar na faculdade... Eu já queria fazer pesquisa, porque eu gosto de ir no detalhe...As vezes eu até nem ia muito bem na faculdade porque eu não conseguia me convencer a ficar só decorando, porque tem uma hora que e só decorar, decorar, decorar...E não da pra você ir no detalhe, na coisa mais [risos] neurótica mesmo, obsessiva...de futucar, futucar, no detalhe porque se não você não consegue ver o todo, né? E isso é importante... Mas eu sempre gostei de ir no detalhe." (S. 3)

Outro grupo de alunos teve experiência com pesquisa ainda no ensino médio. Eles, em geral, alunos de escolas técnicas, eram indicados para estágio na universidade e seguiam na pesquisa. No relato a seguir, um pós-graduando revela seu caminho em direção à pesquisa, iniciado antes mesmo do ensino médio; mostrando como seu interesse e suas dificuldades econômicas e sociais eram o eixo para que ele investisse, fosse sempre além do que lhe parecia possível.

"Eu vim pela escola técnica... Porque lá eles indicavam pra estágios... E eu passei, fiz concurso pra vários lugares, pra indústria que eu trabalhei, pra empresa $\mathrm{X}, \mathrm{Y}$, né... $\mathrm{Na}$ época que eu servi o quartel eu trabalhava num laboratório lá... Mas eu não quis ficar. Não! [sarcástico] Eu adoro os militares! Eles são muito ruins! Muito ruins como pessoas... $\mathrm{Eu}$ tenho muita pena deles... antigamente todo mundo servia... Minha família era muito pobre, eu fui numa esperança grande... E chegando lá eu conheci uma pessoa maravilhosa com quem fiz uma amizade muito grande. Ele fazia um curso técnico e ele me deu a maior força pra fazer a escola técnica... Eu tinha outros colegas que já estudavam lá... Me deram a maior força... A experiência lá foi muito legal. Eu não andava fardado, andava de jaleco, tinha uma autorização pra isso. E...engraçado... minha vida toda - você está fazendo eu repensar isso - minha vida toda sempre ...é [pausa]. Você vê, eu era soldado e trabalhava como técnico, né, depois.. engraçado.. eu sempre fui além do que ...Eu era soldado trabalhava como técnico, depois eu virei técnico, virei professor, virei pesquisador, engraçado, né? [risos]" (S.4)

Em outros relatos foi possível ver a importância do orientador nessa definição profissional. Além do interesse pessoal, esse pós-graduando revela as inúmeras conversas que teve com seu orientador.

"O Y [orientador] ele várias vezes chamava. Primeiro ele insistia, perguntava quase que diariamente se eu queria mesmo ser cientista...Quase que diariamente ele perguntava isso... Eu acho que ele tocava nesse assunto o tempo todo pra me fazer pensar nesse assunto o tempo todo, me fazer refletir sobre isso...E, enfim...na medida em que eu pensasse sobre isso talvez pudesse 
tomar uma decisão mais pensada, ou fazer uma escolha muito mais, melhor pensada. E aí ele perguntava, perguntava, perguntava...e à medida que eu fui sobrevivendo, eu dizia que sim, eu não tinha muita dúvida sobre isso... E tendo sobrevivido a essa etapa ele começou a mencionar a possibilidade de entrar direto pro doutorado." (S.5)

Vemos, portanto, percursos muito singulares na chegada ao mundo da pesquisa. Algumas vezes foi possível ver nossos entrevistados mergulhados em conflitos, como no caso desta doutoranda:

\begin{abstract}
"Escolher ficar aqui não foi fácil, porque eu gosto de Medicina! Não era uma coisa assim: "Ah, não gosto de paciente" e tal... Não! Gosto, eu gosto! Eu faria, eu gosto de clinicar, mas só que eu não consigo ficar sem fazer pesquisa [...] Isso aqui no Brasil, você clinicar e fazer uma pesquisa de qualidade é muito, muito difícil. Então [inaudível] é ficar aqui e depois, quem sabe a gente vai estreitando os, os, os vínculos, né?" (S. 6).
\end{abstract}

Se a pós-graduação, atualmente, figura como requisito fundamental para "tornar-se pesquisador"; para esse grupo a admissão num laboratório era condição para galgar um lugar na pós-graduação. Em alguns casos essa entrada ocorreu precocemente, na iniciação científica (graduandos) ou mesmo antes da entrada na graduação (caso dos alunos de escolas técnicas). Em outros casos, pessoas já graduadas encontraram espaços, via aperfeiçoamento ou apoios semelhantes. De toda maneira, percebe-se, neste caso, a importância das condições existentes (vagas, bolsas, ajuda de custo) no laboratório e departamento, possibilitando (ou não) a permanência na pesquisa.

$\mathrm{O}$ ajuste desses alunos às regras da pós-graduação - ficou claro - era trabalho posterior e também atravessado por inúmeras outras variáveis, como a capacidade de se envolver com os projetos, publicar, "entrar no dia-a-dia do laboratório" e ir aos poucos cumprindo os critérios necessários para a entrada na pós. Quando a admissão não acontecia, era comum ouvir comentários a respeito da ciência como uma atividade "pra poucos mesmo", que nesse campo vivese um "processo de seleção natural", "as pessoas às vezes não se divertem" ali ou percebem que aquilo "não é a sua praia". Em resumo, tais expressões, colhidas junto aos pós-graduandos, revelavam uma idéia subjacente: a ausência de vocação científica.

Peixoto (1994) já indicou a complexidade do tema vocação/talento científico. Em sua pesquisa, os entrevistados (alunos de pós-graduação e docentes pesquisadores) apontaram tanto para o predomínio de aspectos sociais no surgimento da vocação quanto para aspectos individuais. Esta discussão não é negligenciável, pois alguns autores se questionam a respeito da efetiva escolha de uma carreira. Isto foi observado em Carmo (2001) e em Peixoto (1994). Neste último caso, a autora retoma uma pesquisa mais antiga, conduzida por ela própria com graduados em Medicina, onde colheu o seguinte relato:

"Fui "pescado" para pesquisador... O Chagas já havia me "bispado" desde o vestibular. A partir daí, entrei numa roda-viva, e nunca tive sequer a oportunidade de ser médico, nunca vi um doente na minha frente" (p. 233).

Alguns de seus entrevistados afirmaram que o interesse pela pesquisa foi forjado durante a graduação. Embora o tema fosse controverso, a autora percebeu que a maioria dos relatos concentrou-se no caráter inato do talento e da vocação para pesquisa. Esta tendência parece ter sido observada também por Carmo (2001), que encontrou em suas entrevistas expressões como "pesquisador potencial", "verdadeiro cientista", "gênio", etc.

Retomando nossos dados, lembramos que os relatos ouvidos continham expressões próximas (processo de seleção natural, por ex). Além do que foi afirmado naquelas pesquisas - citadas no parágrafo anterior - destacamos uma que é característica dos relatos: a distinção entre "estar formado" e "tornar-se pesquisador independente". Estas expressões eram utilizadas pela maioria dos sujeitos e com grande consistência de significado. A primeira expressão era sempre usada para o final do curso de pós-graduação, ou seja, estar formado significava ter o título de doutor. Este título - era claro para todos - apenas habilitava a começar um caminho na carreira de pesquisador. A segunda, "tornar-se pesquisador independente", revelava-se como atentarmos para o "tornar-se" - uma idéia de processo, ou seja, um pesquisador leva algum tempo para ser assim considerado. Mas quais seriam as sutilezas desse processo?

É importante abrir parênteses aqui, para assinalar que a expressão "tornar-se pesquisador independente" passou a ser considerada uma das evidências da articulação - anteriormente apenas vislumbrada como hipótese - do processo de formação do pesquisador com o processo de trabalho científico. As mudanças observadas no mundo do trabalho científico, já apontadas por vários autores, deixavam claras as suas marcas na formação desses pesquisadores. 
“Tornar-se pesquisador independente" envolvia, enfim, a consecução de vários itens, próprios de um pesquisador estabelecido, a saber:

- publicar sem o auxílio do orientador;

- ter sua própria linha de pesquisa;

- ter seu próprio laboratório;

- obter financiamento,

- orientar alunos de pós-graduação.

Isso tudo, segundo os relatos, era muito trabalhoso. Esses itens, é certo, devem ser considerados a partir das características desse ambiente, onde era possível ver, com freqüência, pesquisadores de diversos níveis (estabelecidos ou não) trabalhando de forma conjunta e com inúmeras colaborações em nível nacional e internacional, o que ampliava consideravelmente as possibilidades e as exigências de publicações, por exemplo.

Além disso, era possível acompanhar, nos laboratórios pesquisados, o que se costumava chamar "orientação em cascata". Através desse tipo de orientação havia um contato maior do orientador com os doutorandos, que por sua vez comunicavam-se mais estreitamente com os mestrandos, bolsistas de aperfeiçoamento, IC (iniciação científica) e assim por diante. Só a partir desses dados era possível compreender os itens anteriormente apontados como pré-requisitos para "tornar-se pesquisador independente". Dito de outra maneira: havia um modo de organizar o trabalho de pesquisa (e a formação), naquele ambiente, que apontava para essas necessidades. Ou seja, os pós-graduandos eram pesquisadores de fato.

É certo que essas características institucionais não destoavam das regras gerais observadas no campo científico nacional: este era um programa de pósgraduação plenamente reconhecido no âmbito da Capes, como referido anteriormente. Suas atividades, portanto, estavam em total sintonia com as diretrizes dos órgãos avaliadores e de fomento, à época da pesquisa.

Retomando os cinco pré-requisitos citados acima, necessários ao "pesquisador independente", podemos dizer que alguns eram alcançados eventualmente pelos estudantes de pós-graduação. A regra geral era que a publicação - em boas revistas de circulação internacional - fosse perseguida como meta e os outros itens fossem gradativamente sendo alcançados. $\mathrm{O}$ item de consecução mais delicada, peça-chave, segundo os sujeitos, era a definição de uma linha de pesquisa. Uma doutoranda nos diz dessa dificuldade, falando do final do doutorado e à saída do laboratório:
"É que nem quando você está na casa de seus pais, você tem comida, seus pais pagam a conta, tem uma hora que você tem que abrir a porta e buscar o seu próprio dinheiro, sua própria pesquisa. E uma coisa que eu acho assim... que eu sofro é: tudo que eu fiz até hoje não é a minha linha, não é o meu trabalho, é o trabalho do $\mathrm{X}$ [orientador]. Então às vezes eu sinto uma cobrança: e agora? Tipo assim: qual vai ser tua linha? Você tem decidir o que que você vai fazer...e eu penso assim... Meu Deus! Eu vou fazer o que eu estou fazendo agora! Eu não sei fazer outra coisa. Eu não tenho uma grande idéia, nenhum megaprojeto, que não sei o quê, entendeu? Às vezes me sinto muito cobrada..." (S. 7).

Essa fala remete diretamente à análise, feita por Reis (1998), em artigo onde articula a qualidade da formação de doutores (área biomédica) ao financiamento da pesquisa em nosso país. O autor ressalta como consequiência de políticas específicas de C\&T brasileiras a grande concentração em temas científicos. Em suas palavras:

[...] o desenvolvimento tecnológico atual da pesquisa biomédica tornou-se extremamente cara [...] As agências de fomento sabem disso e estão financiando preferencialmente os grupos de pesquisa que são internacionalmente visíveis. No entanto, os doutores formados pelo sistema são cada vez mais especialistas e desprovidos de formação geral [...] $\mathrm{O}$ ciclo vicioso leva à formação de cada vez mais pesquisadores que trabalham nos mesmos assuntos, gravitando em torno dos mesmos líderes de pesquisa e de seus colaboradores no exterior. Tanto que na prática, poucos são os assuntos da ciência brasileira. Nas ciências biomédicas, áreas como inflamação e doença de Chagas respondem por uma grande porcentagem do total de pesquisadores, como conseqüência dos "founders effects" (Reis, 1998, p. 25).

Estas observações marcam novamente a articulação formação/trabalho científico. A concentração de temas e a necessidade de agrupamentos cada vez mais extensos de pesquisadores, a nosso juízo, produzem - para o bem e para o mal - efeitos sobre a formação dos pósgraduandos. Um dos aspectos positivos é o incremento da experiência desses estudantes. Com relação ao lado negativo, podemos pensar, ao menos, em situações semelhantes ao caso da doutoranda citada anteriormente (S. 7). Naquele relato, a dificuldade foi 
tomada como questão pessoal; quanto à concentração de temas, na verdade, tem sido uma característica da área.

Vale observar, não obstante, que apenas três sujeitos fizeram referência clara à possibilidade de definição de sua nova linha de pesquisa, ainda durante o doutorado. $\mathrm{O}$ mais comum era observar os doutorandos/mestrandos agregados em torno do orientador e de sua linha de pesquisa. Por isso, talvez a saída do laboratório figurasse como momento crucial. Sair significava ter de sobreviver no meio acadêmico sem a ajuda do orientador ou com menor ajuda. Essa saída, na verdade, era quase sempre gradativa. Os pré-requisitos para "tornar-se pesquisador independente" iam sendo acumulados aos poucos e, em geral, vinham depois de alguns anos de formado, alguns anos depois da obtenção do título de doutor.

Como última questão, mas não menos importante, deve ser ressaltado que a atividade de docência só aparece de maneira periférica nos relatos. Quando isso acontecia, a docência era considerada como via de acesso ao que realmente interessava: a pesquisa. "Tornar-se pesquisador independente", era o que mais almejavam nossos entrevistados. Este era, sem dúvida, o maior signo de distinção (Bourdieu, 1982) para esse grupo, no momento desta pesquisa.

\section{CONSIDERAÇÕES FINAIS}

Em conclusão, pudemos constatar que a escolha da profissão, para nossos sujeitos, era algo que ocorria gradativamente. $\mathrm{O}$ aspecto mais delicado nesse processo, no entanto, era manter a escolha, manter-se no sistema, tal como apontado por Allen-Collinson e Hockey (1998), com relação a pesquisadores contratados no âmbito do Reino Unido. Nossos entrevistados enfrentavam grande competitividade em função do reduzido número de postos de trabalho para todos os que se qualificam, em acordo com Ribeiro (2001). Todos os nossos entrevistados tinham isto claro.

Diante desse quadro, obter o reconhecimento como pesquisador independente era sinal de sucesso; mas vale perguntar: diante das dificuldades e características da organização do trabalho acadêmico/científico em nosso meio, como pensar essa independência? A nosso ver, esse é um paradoxo, forjado durante o processo de ordenação desses sujeitos: por um lado, por necessidades de uma determinada configuração do campo científico, há um chamado à agregação, trabalhos coletivos, interdisciplinares, interinstitucionais; por outro, acompanha-se a solicitação de independência diante de um quadro de empregabilidade bastante difícil para os novos doutores. Talvez em função desse paradoxo, alguns de nossos entrevistados tenham apontado o momento de sair do laboratório como "muito difícil", "angustiante", etc. Este aspecto também foi abordado por Pourmir (1998) com pós-graduandos e postdocs franceses.

Outro aspecto a considerar relaciona-se à iniciação científica ou estímulo à atividade de pesquisa. Por um lado cumpre considerar a influência familiar. A maioria das famílias de nossos entrevistados era de classe média, com pouco ou nenhum envolvimento na atividade. Apenas um dos sujeitos tinha pais pesquisadores. Alguns outros poucos referiram um tio ou irmão nessa atividade. Em que pese a isso, ouvimos de todos que do seio da família veio um valor importante: estudar. Mesmo as famílias mais simples valorizavam os feitos de seus filhos rumo à universidade e à pós-graduação. Por outro lado, vale considerar as condições oferecidas no âmbito da universidade. Talvez se possa levantar a hipótese de que as condições para recepção de alunos (tamanho do laboratório, número de vagas, programas de estágio, fontes de financiamento, etc.), a forma de seleção para admissão nos laboratórios/programas de pesquisa e o interesse pessoal dos candidatos jogam também um papel importante na escolha - gradativa da profissão.

Cabe ressaltar ainda que, dado o material colhido, deve-se avaliar mais cuidadosamente o impacto das políticas públicas (Educação e C\&T, especialmente), das instituições formadoras e dos orientadores sobre esse processo de escolha. Tais avaliações, salvo engano, ainda não ganharam sistematizações em nosso meio. A relevância desse trabalho está posta exatamente no reconhecimento de aspectos sociais envolvidos na determinação das futuras carreiras no mundo da pesquisa. Além disso, a pesquisa oferece subsídios para refletir a respeito do lugar ocupado pelos pós-graduandos na produção e desenvolvimento da ciência brasileira.

Os achados deste trabalho, enfim, devem ser considerados cuidadosamente, tendo-se em vista ele que retrata um universo muito específico da atividade científica. Qualquer tentativa de transposição para outra área deve ser relativizada. Não obstante, pode-se afirmar, de maneira geral, que a escolha da atividade de pesquisa como profissão é atualmente um processo longo, muito marcado pelas regras acadêmicas e pelas mudanças observadas no mundo do trabalho científico. 


\section{REFERÊNCIAS}

Allen-Collinson, J., \& Hockey, J. (1998). Capturing contracts: Informal activity among contract researchers. British Journal of Society Education, 19(4), 497-513.

Alvarez, D. (2004). Cimento não é concreto, tamborim não é pandeiro, pensamento não é dinheiro! Para onde vai a produção acadêmica? Rio de Janeiro: Myrrha.

Bardin, L. (1987). Análise de conteúdo. Lisboa: Edições 70.

Bourdieu, P. (1982). Les rites comme actes d'institution. Actes de la Recherche en Sciences Sociales, 43, 58-63.

Bourdieu, P. (1989). La noblesse d'Etat. Grandes écoles et esprit de corps. Paris: Minuit.

Bourdieu, P. (2001). Science de la science et reflexivité. Paris: Raison d agir.

Carmo, M. S. (2001). O cientista em formação: o quotidiano de uma pós-graduação de excelência (nível 7 CAPES). Dissertação de Mestrado não-publicada, Departamento de Bioquímica Médica, Universidade Federal do Rio de Janeiro, Rio de Janeiro.

Carmo, M. S., De Meis, C., De Meis, L., Lannes, D., \& Velloso, A. (2003). The growing competition in Brazilian science: Rites of passage, stress and burnout. Brazilian Journal of Medical and Biological Research, 36(9), 1135-1141.

Catani, A. M., Oliveira, J. F., \& Dourado, L. F. (2001). Política educacional, mudanças no mundo do trabalho e reforma curricular dos cursos de graduação no Brasil. Educação $e$ Sociedade, 22(75), 67-83.

Hobsbawn, E. (1995). Feiticeiros e aprendizes: as ciências naturais. Em Era dos extremos. O breve século XX: 1914-1991 (M. Santarrita, Trad.). (pp. 504-536). São Paulo: Companhia das Letras.

Jorge, M. J. (1999). Ensino superior e organização da pesquisa: a economia da reforma do ensino no Brasil. História, Ciência, Saúde: Manguinhos, 6(1), 113-132.

Latour, B. (1989). Les professions. En La Science en Action (pp. 236-286). Paris: La Découverte.

Leta, J., \& Meis, L. (1996). A profile of science in Brazil. Scientometrics, 35(1), 33-44.
NSF - National Science Foundation. (2000). Science and Engineering Indicators-2000. Arlington: Division of Science Resources Statistics.

NRC - National Research Council. (1998). Trends in the early careers of life scientists. Committee on Dimensions, Causes, and Implications of Recent Trends in Careers of Life Scientists.

Peixoto, M. C. L. (1994). Escola de pesquisar: estudo sobre a formação do pesquisador. Tese de Doutorado não-publicada, Faculdade de Educação, Universidade Federal do Rio de Janeiro, Rio de Janeiro.

Pereira Neto, A. F. (1997). Tornar-se cientista: o ponto de vista de Bruno Latour. Cadernos de Saúde Pública, 13(1), 109-118.

Pourmir, I. (1998). Jeune chercheur. Souffrance identitaire et désarroi social. Paris/Montreal: L’Harmattan.

Reis, G. A.(1998). A qualidade da formação de doutores e o financiamento a grupos de pesquisa no Brasil: as relações óbvias e as nem tanto. Em M. Palatnik, P. Arruda, J. Leta, F. Leite \& L. De Meis (Orgs), A pós-graduação no Brasil. Rio de Janeiro: EdUFRJ.

Ribeiro, S. P. (2001). Jovens doutores recebem apoio após publicação do Manifesto na Nature. Recuperado em 30 de fevereiro, 2000, de www.comciencia.br/noticias/05out01/ servio.htm (Entrevista).

Seligmann-Silva, E. (1994). Desgaste mental no trabalho dominado. Rio de Janeiro: Editora UFRJ \& Cortez Editora.

Slaugter, S., \& Leslie, L. L. (1999). Academic capitalism. Politics, policies and the entrepreneurial university. Baltimore/London: Jonhs Hopkins University.

Teichler, V. (1997). Graduate employment: Challenges for higher education in the twenty-first century. Higher Education in Europe, 22(1), 75-84.

Weber, M. (1982). A ciência como vocação. Em Ensaios de Sociologia (pp. 154-183). Rio de Janeiro: Guanabara.

Recebido em 09/06/2007 Aceito em 21/11/2007

Endereço para correspondência : Rita de Cássia Ramos Louzada. Av. Venceslau Braz, 71, fundos, Botafogo, CEP 22290-140, Rio de Janeiro-RJ.E-mail: ritacrl@uol.com.br 